\title{
Staging of lung cancer: the role of noninvasive, minimally invasive and invasive techniques
}

\author{
Georgios Stamatis
}

\author{
Number 10 in the series "Challenges and controversies in thoracic oncology" \\ Edited by J-P. Sculier, B. Besse and P. Van Schil
}

Affiliation:

Dept of Thoracic Surgery and Endoscopy, Ruhrlandklinik, West German Lung Center of the University Duisburg Essen, Essen, Germany.

Correspondence:

Georgios Stamatis, FECTS, Dept of Thoracic Surgery and Endoscopy, Ruhrlandklinik, West German Lung Center of the University Duisburg Essen, Tueschener Weg 40, 45239 Essen, Germany.

E-mail: georgios.stamatisaruhrlandklinik.uk-essen.de

ABSTRACT Accurate staging and restaging of primary tumour and mediastinal nodes in patients with lung cancer is of significant importance. For primary tumours, computed tomography (CT) scans of the chest are recommended. Positron emission tomography (PET) imaging should be used in patients with curative intent treatment to evaluate metastatic disease. Diagnosis of the primary tumour should be performed using bronchoscopy or CT-guided transthoracic needle aspiration. In patients with enlarged mediastinal nodes and no distant metastasis, invasive staging of the mediastinum is required. For suspicious $\mathrm{N} 2$ or N3 disease, endoscopic needle techniques, such as endobronchial ultrasound and transbronchial needle aspiration, oesophageal ultrasound and fine needle aspiration, or a combination of both, are preferred to any surgical staging technique. In cases of suspicious nodes and negative results using needle aspiration techniques, invasive surgical staging using mediastinoscopy or video-assisted thoracic surgery should be performed. In central tumours or N1 nodes, preoperative invasive staging is indicated.

Restaging after induction therapy remains a controversial topic. Today, neither CT, PET nor PET/CT scans are accurate enough to make final further therapeutic decisions for mediastinal nodal involvement. An invasive technique providing cytohistological information is still recommended.

@ERSpublications

What are the roles of noninvasive, minimally invasive and invasive techniques in the staging of lung cancer? http://ow.ly/LXa6b

\begin{abstract}
Previous articles in this series: No. 1: Powell HA, Baldwin DR. Multidisciplinary team management in thoracic oncology: more than just a concept? Eur Respir J 2014; 43: 1776-1786. No. 2: Shlomi D, Ben-Avi R, Balmor GR, et al. Screening for lung cancer: time for large-scale screening by chest computed tomography. Eur Respir J 2014; 44: 217-238. No. 3: De Ruysscher D, Nakagawa K, Asamura H. Surgical and nonsurgical approaches to small-size nonsmall cell lung cancer. Eur Respir J 2014; 44: 483-494. No. 4: Van Schil PE, Opitz I, Weder W, et al. Multimodal management of malignant pleural mesothelioma: where are we today? Eur Respir J 2014; 44: 754-764. No. 5: Kim L, Tsao MS. Tumour tissue sampling for lung cancer management in the era of personalised therapy: what is good enough for molecular testing? Eur Respir J 2014; 44: 1011-1022. No. 6: Blum T, Schönfeld N. The lung cancer patient, the pneumologist and palliative care: a developing alliance. Eur Respir J 2015; 45: 211-226. No. 7: Paesmans M, Grigoriu B, Ocak S, et al. Systematic qualitative review of randomised trials conducted in nonsmall cell lung cancer with a noninferiority or equivalence design. Eur Respir J 2015; 45: 511-524. No. 8: Grigoriu B, Berghmans T, Meert A-P. Management of EGFR mutated nonsmall cell lung carcinoma patients. Eur Respir J 2015; 45: 1132-1141. No. 9: Duchemann B, Friboulet L, Besse B. Therapeutic management of $\mathrm{ALK}^{+}$nonsmall cell lung cancer patients. Eur Respir J 2015; 46: $230-242$.
\end{abstract}

Received: July 102014 | Accepted after revision: April 072015 | First published online: May 142015

Conflict of interest: None declared.

Copyright CERS 2015 


\section{Introduction}

Lung cancer represents the most common cause of death among patients with malignant disease in industrialised countries [1,2]. Nonsmall cell lung cancer (NSCLC) accounts for nearly 85\% of all lung cancer cases [3]. Correct staging of patients with lung cancer provides accurate information on the local and distant extent of the disease, guides the choice of treatment and enables an estimation of prognosis. Methods of staging include: imaging, such as computed tomography (CT), 2-deoxy-2-( $\left.{ }^{18} \mathrm{~F}\right)$ fluoro-D-glucose positron emission tomography (FDG-PET) or integrated FDG-PET/CT scan; needle-based biopsy techniques, such as endobronchial ultrasound transbronchial needle aspiration (EBUS-TBNA) or oesophageal ultrasound needle aspiration (EUS-NA); transbronchial needle aspiration (TBNA) and CT-guided transthoracic fine needle aspiration (TTFNA); and finally surgical techniques, including mediastinoscopy, mediastinotomy or video-assisted thoracoscopic (VATS) techniques. Complete resection is an essential factor for potential cure. While in the early stages I and II, surgery has been accepted as the major curative treatment, locally advanced stages IIIA and IIIB are rarely cured by local treatment modalities, such as surgery or radiotherapy alone. Various multimodality protocols in these stages, including chemotherapy and radiotherapy, have resulted in increased survival rates, although in some subgroups additional surgery was performed [4-7]. Therefore, an important aim of staging procedures will be to select candidates for primary surgery or, in stage IIIA/IIIB disease, for multidisciplinary decision. Furthermore, the additional question of whether restaging techniques can provide the clinician with information about the prediction of response of the primary tumour and mediastinal nodes remains to be answered.

The aim of this review is to evaluate and update the role of noninvasive, minimally invasive and invasive techniques in the staging and restaging of lung cancer. Parameters that were evaluated were sensitivity, specificity, false-negative and false-positive rate, and accuracy. In this manuscript, guidelines and recommendations of the European Society of Thoracic Surgeons (ESTS), the American College of Chest Physicians, the International Association for the Study of Lung Cancer (IASLC) and the German Cancer Society were taken into consideration.

\section{Staging of lung cancer}

Diagnosis of primary tumour (T-status)

Posteroanterior and lateral radiograms remain the most common radiological examinations for thoracic diseases and the initial available diagnostic tool if lung cancer is suspected in most countries. Suspected lesion or mass, atelectasis, enlargement of the mediastinum or pleural effusion are findings that prompt extensive diagnostic evaluation. In patients with suspected lung cancer, a CT scan of the chest with contrast, including the upper abdomen with the liver and adrenal glands, is strongly recommended [8]. CT scans can help not only in tumour diagnosis, but also in correlation with the tumour size and extent, to structure the clinical evaluation and tumour staging. CT scan is quite sensitive in detecting tumour mass for centrally located tumours, and also for peripheral pulmonary nodules. Only a few studies have analysed the criteria for malignancy and reported that imaging tests are highly sensitive for identifying malignant solitary nodules, but the specificity is variable and often poor (sensitivity, 98-100\%; specificity, 54-93\%) [9]. Due to the precise information about the location of the lesion, a CT scan has to be done before invasive examinations as bronchoscopy or mediastinoscopy are performed

Magnetic resonance imaging (MRI) is used in the staging of lung cancer for better representation of the anatomical relationship between the tumour and the chest wall or/and the mediastinal structures, due to the higher contrast of soft tissue. This advantageous effect in association with the absence of artefact formations in the cervicothoracic passage, the neuroforamina and the spinal channel ranks, MRI is the first choice in imaging of sulcus superior tumours and shows contact or infiltration of the vertebral column $[10,11]$.

FDG-PET imaging can provide metabolic information about the primary tumour, the mediastinal nodes and any distant metastasis. The importance of FDG-PET in reflection of the primary tumour is different. In the assessment of tumour mass, the difference between tumour and atelectasis can be seen; for solitary pulmonary lesions the size of the tumour is important. The prevalence of malignancy varies by size $(0-1 \%$ for nodules $<5 \mathrm{~mm}, 6-28 \%$ for nodules $5-10 \mathrm{~mm}$, and $64-82 \%$ for nodules $>20 \mathrm{~mm}$ ). The sensitivity of FDG-PET for identifying a malignant solitary lesion is consistently high $(80-100 \%)$, whereas the specificity is lower and more variable across studies (40\%-100\%) $[9,12,13]$.

Bronchoscopy is the most important diagnostic method, particularly in centrally located tumours, where the accuracy rate is close to $100 \%$ [14]. In peripheral tumours, the combination of different additional biopsy techniques, such as catheters, brushes, needles or forceps, is necessary. Modern navigation techniques for the diagnosis of small pulmonary nodules could increase the diagnostic accuracy $[15,16]$.

The reliability of oesophageal ultrasound and fine needle aspiration (EUS-FNA) for staging the direct tumour invasion into the mediastinum ( $\mathrm{T}$ staging) was evaluated in one study. The authors reported a 
false-negative rate of about $30 \%$, indicating that this technique should not be recommended for assessing mediastinal invasion for primary tumours [17].

In studies of CT-guided needle biopsy (TTFNA), the sensitivity and specificity were excellent (90\%) when biopsy yielded a specific benign or malignant result. Particularly in lesions less than $3 \mathrm{~cm}$, TTFNA resulted in higher sensitivity rates than bronchoscopy [18]. The most common complication was pneumothorax, which was reported in about $10 \%-30 \%$ of cases $[19,20]$.

Finally, VATS has been used to evaluate T4-tumours described by CT scan, meaning that an interdisciplinary multimodality concept can be introduced. Involvement of T4 structures could be found in $38 \%$ of patients, and a malignant pleural effusion in $6 \%$. In $4 \%$ of the patients, unsuspected malignant pleural findings are described $[21,22]$.

\section{Diagnosis for lymph nodes ( $\mathrm{N}$-status)}

The extent of lymph node involvement in patients with NSCLC is the most important prognostic factor and influences different therapeutic strategies. Patients with clinical N1, N2 and N3 disease are heterogeneous groups with different outcomes and survival. In cases of hilar lymph node enlargement ( $>1 \mathrm{~cm}$ in short axis) on the CT scan, and in the absence of evidence of mediastinal or distant metastasis, the evaluation of the hilar lymph nodes status is not recommended, because these nodes can be removed during lung resection. An exception is represented by patients with the involvement of multiple hilar nodes or bulky hilar disease. Instead these patients are candidates for neoadjuvant treatment [23]. In the subgroups of patients with IIIA-N2 disease, induction chemotherapy combined with radiotherapy and surgery has proven to be effective [24-27]. In patients with N3 disease, some studies with a limited number of patients have shown a down-staging effect after combined chemo-radiation, meaning that selected patients underwent surgery with encouraging results [28-30].

The IASLC recommendations effected several modifications in the lymph node map compared with the previous maps of NARUKe et al. [31] and Mountain and DresLer [32]. First, the difference between nodal zone and nodal station is defined and the anatomical borders of the nodal stations are clearly described [33]. A nodal zone is described as an anatomical area including one or more neighbouring nodal stations (the aortopulmonary zone includes the subaortic and para-aortic nodal stations 5 and 6, the lower zone the paraoesophageal and pulmonary ligaments stations 8 and 9, etc.). Secondly, a shift of the anatomical mediastinal midline to the left paratracheal margin was introduced (oncological mediastinal midline) affecting the nodal stations $2 \mathrm{R} / \mathrm{L}$ and $4 \mathrm{R} / \mathrm{L}$. This means that right-sided tumours, those involving pretracheal lymph nodes or lymph nodes on the left anatomical midline (right oncological midline) are classified as N2 disease, while those cases of left-sided tumours are classified as N3 [34].

Noninvasive techniques

CT still presents the major imaging investigation for the primary tumour as well as for mediastinal nodes. CT scan is accurate for describing nodal size ( $>1 \mathrm{~cm}$ diameter in the short axis), but the clinical relevance of nodal enlargement for staging is limited because of the low sensitivity of $57 \%$ and the positive predictive value (PPV) of only 56\%. Additionally the clinical relevance of lymph nodes enlargement for staging is unsatisfactory because tumour involvement was also found in up to $20 \%$ of small nodes (negative predictive value (NPV) of 83\%) [35].

The use of FDG-PET has resulted in an improvement in the accuracy of lung cancer staging. Different studies have demonstrated that FDG-PET is superior to CT for mediastinal staging, with rates of sensitivity and NPV of $85 \%$ and $93 \%$ respectively, comparable to the rates of mediastinoscopy. However, because of the positive FDG uptake by inflammatory processes, the specificity and PPV of FDG-PET are lower than those of mediastinoscopy and EBUS-TBNA. In clinical stage IA, with the intention of curative treatment, a FDG-PET scan can be performed for mediastinal and extrathoracic staging. In clinical stage IB-IIIB, with intention of curative treatment, a FDG-PET scan is strongly recommended [36].

A further technical development is the integrated FDG-PET/CT scan, in which the high sensitivity of FDG-PET and the excellent morphological resolution and anatomical detail description of CT scan are fused. Due to the more precise anatomical correlation between tumour and atelectasis, and regional relationship between the involved lymph nodes and the surrounding mediastinal tissue and structures, several studies have shown an increased diagnostic accuracy of integrated FDG-PET/CT scan comparable to FDG-PET alone [37-40].

In 2007 and 2014 the ESTS council published guidelines for preoperative lymph node staging for NSCLC. The working group recommended that in patients with clinical stage I NSCLC and negative mediastinal FDG-PET images, invasive staging techniques like mediastinoscopy can generally be omitted [34, 40]. Invasive mediastinal staging is recommended in cases with $\mathrm{N} 1$ suspected nodes, in tumours $>3 \mathrm{~cm}$ and in 
centrally located tumours without suspected nodes on CT scan or FDG-PET images [40]. In 30\% of patients with N1 disease on CT scan, involved N2 or N3 nodes were found [41]. For tumours $>3 \mathrm{~cm}$, particularly adenocarcinomas with high FDG uptake, further invasive staging techniques for the mediastinal nodes should be considered [42]. Finally, the prevalence of pathological N2 disease in central tumours was found to be as high as $22 \%$; therefore, in this group, more accurate lymph node staging using invasive techniques is required [43].

Minimally invasive techniques

Minimally invasive techniques or invasive nonsurgical techniques are needle-based biopsy techniques. TBNA is used only in some centres and the reported accuracy for mediastinal staging in NSCLC varies widely. HoLTy et al. [44] performed a meta-analysis and found that the sensitivity of TBNA is critically dependent on the prevalence of mediastinal metastasis. When properly performed, TBNA was highly specific for identifying mediastinal metastasis in patients with NSCLC, but because of the low sensitivity and high false-negative rates of $78 \%$ and $28 \%$, respectively, the TBNA technique could not be established as a routine diagnostic method in the staging of lung cancer. Today, EBUS-TBNA and EUS-NA have completely replaced TBNA for mediastinal staging of lung cancer.

The use of endobronchial and endo-oesophageal ultrasound needle aspiration techniques has rapidly increased since different societies published guidelines regarding staging methods for NSCLC [8, 36, 40]. EBUS-guided TBNA is mainly suitable for the mediastinal lymph node stations $2 \mathrm{R} / \mathrm{L}, 4 \mathrm{R} / \mathrm{L}$ and 7 , as well for the hilar lymph node stations 10, 11 and 12. Most studies using EBUS-TBNA have involved patients with discrete lymph node enlargement on the CT scan or FDG-PET scan and a median disease prevalence of approximately 58\%. The overall median sensitivity was 89\% (range 46-97\%) and the median NPV was 91\% (range 60-99\%). A systematic approach of all lymph nodes stations could not be reached in all studies, but following the evaluation of $\mathrm{N} 2$ or N3 disease, only small differences between the systematic and the selective approach were reported $[36,45,46]$.

The yield of EUS-guided FNA is particularly suitable for assessment in the posterior part of the levels $4 \mathrm{~L}$, 5 and 7 and the inferior mediastinal levels 8 and 9. Examination of the left adrenal gland, coeliac lymph nodes and the liver is also possible. This procedure requires skilled and experienced investigators. The overall prevalence in the published studies was $58 \%$, the median sensitivity was $89 \%$ (range $50-100 \%$ ), the median specificity was $100 \%$, and the median NPV was $86 \%$ (range 68-100\%) respectively [36, 47, 48]. Complications such as bleeding or infection are rare and no mortality for either ultrasound guided needle technique has been reported.

The combined use of EBUS-TBNA/EUS-NA results in a near-complete assessment of all mediastinal lymph nodes, with exception of stations 5 and 6 . The median sensitivity and specificity were $91 \%$ and $100 \%$, respectively, and the median NPV was 96\% [49-52]. In a further randomised study, minimally invasive endosonography followed by surgical staging, if nodal involvement was not found, was compared to surgical staging alone. Sensitivity was $79 \%$ in the surgical staging group versus $85 \%$ in endosonography and $94 \%$ in the combining endosonography/surgical group. Combining endosonography and surgical staging also resulted in fewer unnecessary thoracotomies [51].

\section{Invasive techniques}

Cervical mediastinoscopy was introduced by Carlens in 1959 and, until the distribution of the video-assisted mediastinoscopy (VAM) in 1995 and the use of the endobronchial and endo-oesophageal ultrasound needle aspiration techniques in 2005, this was the gold standard for invasive complete staging of the upper mediastinum in patients with potentially operable lung cancer. Mediastinoscopy is performed under general anaesthesia in the operating room and in most hospitals as an outpatient procedure. According to the lymph node map proposed by IASLC [33], right and left upper and lower paratracheal stations $(2 \mathrm{R} / \mathrm{L}$ and $4 \mathrm{R} / \mathrm{L})$, the pretracheal station 3 and the subcarinal station 7 can be evaluated. Morbidity and mortality rates are low, with an average of $2 \%$ and less than $0.1 \%$ respectively. The median sensitivity of cervical mediastinoscopy was $78 \%$ and the median NPV was $91 \%$ in 9267 patients, according to data published by SILVESTRI et al. [36]. Approximately $42 \%-57 \%$ of false-negative biopsies resulted in nodal stations that were not reached by cervical mediastinoscopy (stations 5, 6, 7 posteriorly and stations 8 and 9). The advantage of VAM is the improved visualisation of the operative field, leading to a higher accuracy and the possibility of teaching this technique without compromising the safety of the procedure $[53,54]$. An additional advantage is the clear removal of the subcarinal lymph node (station 7) and the safe visualisation of the oesophagus [55]. ZAKKAR et al. [56] analysed 108 papers published between 1989 and 2011 reporting on conventional mediastinoscopy and VAM; both procedures showed no mortality and a low morbidity, although more lymph node stations could be removed by the VAM. There were no differences in the accuracy or NPV. 
Extended cervical mediastinoscopy through a suprasternal approach lateral to the aortic arch, first described by GinsBerg et al. [57], is used to assess the subaortic and paraaortic nodal stations 5 and 6 in addition to the classical paratracheal and subcarinal lymph node stations reached by cervival mediastinoscopy. The median sensitivity was $71 \%$ and the median NPV was $91 \%$. Because of the demanding technical approach, only a few institutions with large experience in cervical mediastinoscopy have routinely used this procedure. For lymph node stations 5 and 6, the left anterior mediastinotomy, first described by Chamberlain, offers a safe approach to these stations. It is used predominantly for mediastinal staging of tumours of the left upper lobe. This procedure requires general anaesthesia with double lumen tube and in most hospitals is used as an outpatient procedure. At the end of the operation, the chest tube can be removed after hyperinflation of the lungs. The median sensitivity was approximately $71 \%$ and the NPV was $91 \%$ with a prevalence of $26 \%[58,59]$.

In addition to VAM, some groups have developed extended techniques for mediastinal lymphadenectomy through a cervical approach. Using video-assisted mediastinoscopic lymphadenectomy a complete lymphadenectomy of lymph nodes of stations 2 and 4 bilateral, 7 and 8 is possible. Transcervical extended mediastinal lymphadenectomy (TEMLA) is a more radical procedure, and is performed through a small collar incision in the neck. The sternal manubrium is elevated with a special retractor and bilateral visualisation of the laryngeal recurrent and vagus nerves is possible. This enables complete removal of all mediastinal nodal stations (1, 2, 3A, 3P, 4, 5, 6, 7 and 8) except for the pulmonary ligament nodes (station 9) and the most distal left paratracheal nodes (station $4 \mathrm{~L}$ ). Some authors used these techniques not only as staging procedure, but also as radical lymphadenectomy before anatomical lung resection. The advantage for both methods is the reduction of false-negative results because of potential micrometastasis in the removed nodes. In both procedures, a high accuracy between $96 \%$ and $98 \%$ and NPV between $97 \%$ and $99 \%$ has been reported [60-62].

VATS can also contribute to complete mediastinal staging because all mediastinal nodes can be assessed. General anaesthesia and a double lumen tube are necessary; in some cases, it is difficult to reach the left paratracheal nodes. Morbidity and mortality are extremely low: $2 \%$ and $0 \%$, respectively. The median value of sensitivity is $99 \%$ and the NPV $96 \%$ (4\% false-negative rate) $[63,64]$.

\section{Distant metastasis}

Independent of tumour stage, if extrathoracic metastases are suspected, imaging techniques are required. In clinical stage IIB-IIIB disease with intended curative treatment, extrathoracic imaging using FDG-PET scan or integrated FDG-PET/CT scan and head MRI is indicated, even if clinical symptoms were absent. FDG-PET imaging led to a higher rate of correct identification of M1b disease [65]. If FDG-PET scan is not available or for different reasons cannot be carried out, bone scan and abdominal ultrasound is recommended [8].

\section{Restaging of lung cancer}

In about $50-80 \%$ of patients with NSCLC IIIA/IIIB disease induction chemotherapy or combined chemoradiotherapy resulted in tumour response and the clearance of involved N2 or N3 lymph nodes. In selected cases additional surgery showed encouraging results with long-term survival $[5-8,66]$. Patients with non-response of the primary tumour or persisting mediastinal node involvement have a worse prognosis compared with those with proven pulmonary and mediastinal down-staging [67-69]. Restaging is important because resection after induction treatment may be associated with an increased postoperative morbidity and mortality compared with patients having surgery alone [70, 71]. Restaging tests include CT scan, FDG-PET or integrated FDG-PET/CT scan, endoscopic methods of needle aspiration (EBUS-TBNA or EUS-FNA) and invasive surgical methods such as mediastinoscopy, repeat mediastinoscopy and VATS.

\section{Diagnosis for primary tumour (T-status)}

In the restaging of primary tumour, most studies involving CT scans have shown variability in the specificity and false-negative rates for the detection of residual cancer with a median of $31 \%$ and $54 \%$ respectively (range $0-100 \%$ ). The false-negative rates by CT scan were higher after chemotherapy alone than after combined chemoradiotherapy $[72,73]$. An important observation in patients during neoadjuvant treatment is the asymptomatous course of pulmonary embolism. We found, during restaging on CT scan or in the perfusion scan, a partial or complete segmental failure in one or both lungs in $12 \%$ of patients [74].

Most of the PET studies showed a better reliability for detection of residual tumour than CT scan $[73,75,76]$ The average at primary site for sensitivity, specificity, false-negative and -positive rates amounted to $76 \%$, $71 \%, 36 \%$ and $12 \%$, respectively. The false-negative rates varied between 13 and $100 \%$, the median rate of $36 \%$ is disappointingly high. According to the false-positive rates, there is no difference in the quantitative PET assessment between patients after chemotherapy and those after chemoradiotherapy. However the change in the standardised uptake values (SUV) has been correlated with pathological changes of the primary 
tumour. CERFOLIO et al. [73] described that the change in the maximum SUV had a linear relationship to the percentage of nonviable tumour cells in the resected lungs, indicating that FDG-PET scan is a more accurate predictor than a change in size shown on the CT scan. Additionally, it was found that when the maximum SUV decreased by $80 \%$ or more, it was more likely that the patient was a complete responder, irrespective of cell type.

Bronchoscopy is useful for re-evaluating tumour response in the central airways and defining local operability. For centrally located tumours with endobronchial growth, flexible or rigid bronchoscopy with biopsies of the prospective resection margins is recommended [74].

\section{Diagnosis for mediastinal nodes ( $\mathrm{N}$-status)}

Studies evaluating the reliability of mediastinal restaging by CT scan showed a lower sensitivity, specificity and accuracy than by primary staging, indicating that CT scan is not appropriate for identifying patients with partial or complete response of the involved mediastinal nodes. Relating to median false-negative rates of $31 \%$ and false-positive rates of $34-66 \%$, CT imaging is unable to predict the tumour viability after chemotherapy or chemoradiotherapy [77-79].

PET scan is less sensitive in the restaging of mediastinal lymph nodes after chemotherapy or chemoradiotherapy than before induction treatment, with higher false-negative rates, ranging from $28 \%$ to $36 \%$. A potential reason for these poor results could be changes in the tumour, such as fibrosis of the surrounding tissue and altered perfusion due to the induction treatment $[75,76]$. There were no differences found between patients after chemotherapy alone and those after combined chemoradiotherapy. The reported sensitivity was $50 \%-60 \%$ and the specificity was $85-90 \%$. The optimal timing of PET restaging was recommended to be 1 month after the end of induction therapy [79]. It should be mentioned that maximum SUV values depend on the local apparatus and settings; therefore, the absolute values cannot be extrapolated to other centres.

The use of an integrated FDG-PET/CT scan has been reported in two studies. Due to the better localisation of focal FDG uptake in the mediastinum, the specificity significantly increased to $93 \%$ and the false-negative rate decreased to $13 \%$ [80]. SUV maximum values from two serial PET/CT scans, before and after three chemotherapy cycles, allowed prediction of the histopathological response in the primary tumour and mediastinal lymph nodes (sensitivity and specificity of $73 \%$ and $89 \%$, respectively) and had a prognostic value [81]. In another study, repeat PET/CT was found to be more accurate than CT alone for all pathological stages [82]. As a result of the $25 \%$ false-positive rate and $20 \%$ false-negative rate in cases of suspicious residual tumour in the mediastinal nodes, invasive techniques for nodal staging are required [34].

A limited number of groups have reported their experiences with needle aspiration techniques in the evaluation of mediastinal nodes after induction treatment. Endoscopic EBUS-TBNA and EUS-FNA techniques for restaging showed different results in relation to the NPV, due to the different prevalence of N2 disease and the selective approach only of a small number of nodal stations per patient (average of one to two nodal stations per patient). The reported NPV varied between $20 \%$ and $78 \%$, indicating that in the case of negative endoscopic needle aspiration results, invasive surgical mediastinal restaging should be confirmed [83-85].

In one study with only 11 patients, TBNA without visualisation resulted in a false-negative rate of $0 \%$, which can be explained by the small number of patients and the selection of one nodal station with persistently enlarged mediastinal nodes [86].

Repeat mediastinoscopy (reMS) as a restaging procedure was reported only by a small number of surgeons and was rarely performed before neoadjuvant protocols were introduced in the treatment of locally advanced lung cancer. ReMS was considered technically demanding because of tissue adhesions that were encountered, particularly between trachea and innominate artery. However reMS was feasible in up to $98 \%$ of cases. Mortality was almost zero, and morbidity was very low (1.9\%). Sensitivity rates were 29-76\%, specificity was 100\%, and accuracy was 60-93\%. PPV and NPV values reached $100 \%$ and $85 \%$, respectively. Accuracy and sensitivity were lower than reported for the initial mediastinoscopy for primary staging, due to adhesions and severe fibrosis. The number of removed or biopsied lymph nodes varied in the published series, but was significantly higher, than in the endoscopic needle aspiration techniques. Persisting nodal disease at repeat mediastinoscopy carries a poor survival in the majority of cases because of occult metastases; therefore, indication for surgical intervention in such an unfavourable group of patients should be evaluated very carefully [80, 87-90].

There are two reports from the same group with experience of TEMLA as a restaging technique. In the first study, only seven out of 63 patients had a previous mediastinoscopy before induction chemotherapy or chemoradiotherapy. Sensitivity, specificity and accuracy were 95.5\%, 100\% and $98.3 \%$ respectively; the NPV was $97.4 \%$ and PPV was $100 \%$ [91]. In the second report, EBUS/EUS needle techniques were 


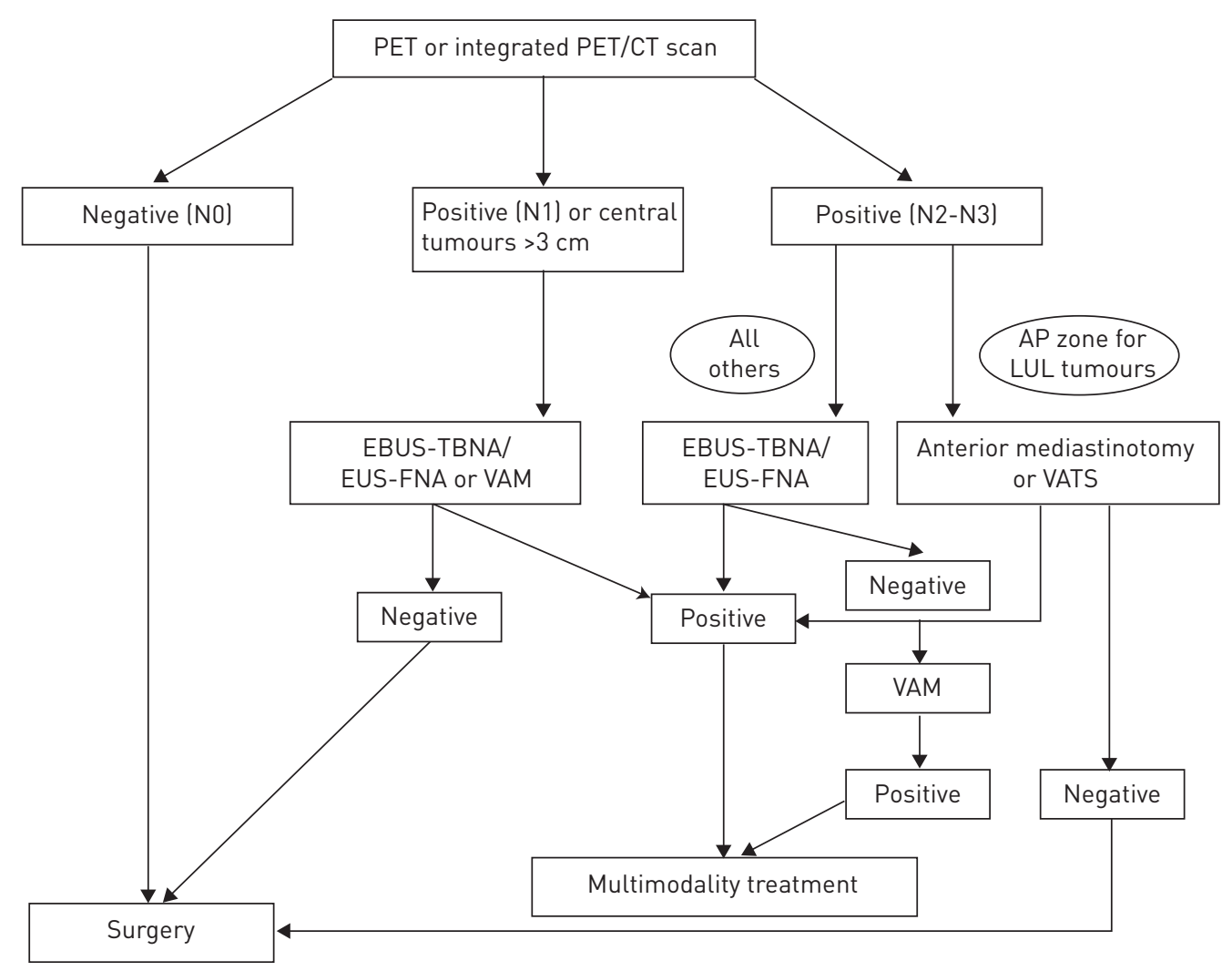

FIGURE 1 Algorithm for primary mediastinal lymph node staging. PET: positron emission tomography; CT: computed tomography; AP: aortopulmonary; LUL: left upper lobe; EBUS-TBNA: endobronchial ultrasound and transbronchial needle aspiration; EUS-FNA: oesophageal ultrasound and fine needle aspiration; VAM: video-assisted mediastinoscopy; VATS: video-assisted thoracic surgery.

compared with TEMLA. In the restaging group, endoscopic staging was performed in 88 patients and TEMLA in 78 patients. There was a significant difference between EBUS or EUS and TEMLA for sensitivity $(64.3 \%$ and $100 \%$; $\mathrm{p}<0.01)$ and NPV $(82.1 \%$ and $100 \%$; $<0.01)$ in favour of TEMLA [92].

Finally, the first cervical mediastinoscopy as a restaging procedure was reported by LARDINOIs et al. [53]. In 195 patients without pretreatment and 24 patients after the completion of induction therapy, mediastinal lymph nodes were biopsied using a video-assisted approach. The accuracy of video mediastinoscopy was assessed for each patient according to the results obtained from mediastinal lymph node dissection performed during lung resection. Video mediastinoscopy in patients without pretreatment revealed sensitivity, specificity, and accuracy of $87 \%, 100 \%$, and $95.6 \%$, respectively; in patients after induction therapy, these results were $81 \%, 100 \%$, and $91 \%$, respectively. In a systematic review of restaging after induction treatment for stage III (N2) lung cancer, CANDELA et al. [93] compared restaging diagnostical methods with pathological results at surgery. Although restaging methods are commonly used to select or exclude patients from surgery, the data showed them to be quite unreliable. Compared with CT, PET, reMs, EBUS or EUS (false-negative rate of $15 \%-30 \%$ ), primary mediastinoscopy seems to be the most reliable method for re-assessment of N2 disease.

The only VATS study for mediastinal restaging was reported by JAKLITSCH et al. [94]. In a prospective multi-institutional trial, the feasibility of video thoracoscopy to restage the ipsilateral nodes in mediastinoscopy staged IIIA (N2) NSCLC was proven. A total of 47 video thoracoscopy procedures (69\%) restaged the mediastinum. Video thoracoscopy was unsuccessful in 21 patients (31\%). The sensitivity was $67 \%$, the specificity $100 \%$ and the NPV $73 \%$. Video thoracoscopy restaging was limited by radiation and was unable to reach the $4 \mathrm{R}$ nodal station.

\section{Summary for first staging and restaging}

For patients with either a known or suspected lung cancer that are eligible for treatment, CT scan of the chest and upper abdomen including the liver and adrenal glands is recommended. Diagnosis of the primary tumour should be performed using bronchoscopy or CT-guided TTFNA. PET imaging, if available, should be used in patients with curative intent treatment to evaluate metastatic disease. Head 


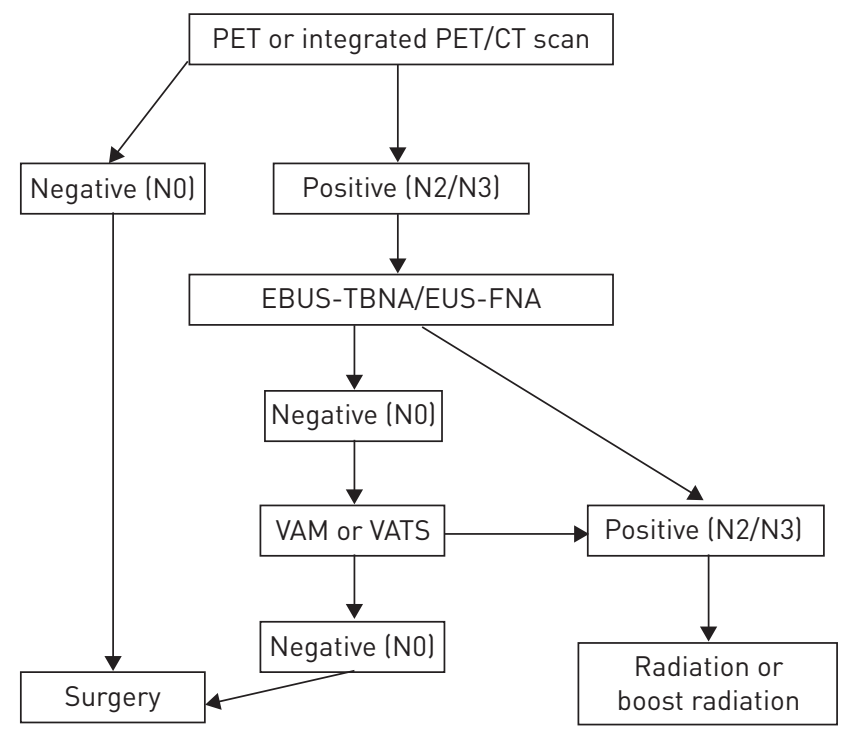

FIGURE 2 Algorithm for mediastinal lymph node restaging after induction treatment. PET: positron emission tomography; CT: computed tomography; EBUS-TBNA: endobronchial ultrasound and transbronchial needle aspiration; EUS-FNA: oesophageal ultrasound and fine needle aspiration; VAM: video-assisted mediastinoscopy; VATS: video-assisted thoracic surgery.

MRI (or CT scan if not available) in patients with III or IV stage disease should be performed, even without any clinical symptoms. In patients with enlarged mediastinal nodes and no distant metastasis, with or without increased PET uptake, invasive staging of the mediastinum is recommended. For suspicious $\mathrm{N} 2$ or N3 disease, endoscopic needle techniques, such as EBUS-TBNA, EUS-FNA or a combination of these two methods, is preferred to any surgical staging technique. In cases of negative results using needle aspiration techniques and suspicious nodes, invasive surgical staging using mediastinoscopy or VATS should be performed. In patients with NSCLC in the left lung and potentially curative treatment, invasive approach of the nodal station 5 and 6 via Chamberlain procedure, VATS or extended cervical mediastinoscopy is required. Imaging findings suggestive of distant metastatic disease need further evaluation and tissue histology only in patients with curative intent treatment (fig. 1).

Recommendations about restaging are difficult to define because high false-positive and -negative rates between $20 \%$ and $30 \%$ have been reported, despite the variety of available techniques. Also in experienced centres a number of down-staged patients have been first identified in the histopathological specimens after resection. CT scan of the chest and upper abdomen is the most widespread method for predicting radiographic response of the primary tumour after induction treatment. However, CT scan cannot predict complete eradication of viable tumour. PET imaging or integrated PET/CT-scan is also commonly used, but radiotherapy can cause pathological uptake due to inflammation; therefore, this method is also not sufficiently reliable. ReMs has been proven to be safe and feasible in experienced centres, but due to adhesions and fibrosis, the approach is technically challenging and the false-negative rate of up to $25 \%$ disappointing. The experience with EBUS-TBNA and EUS-FNA is still limited; the reported false-negative rate of $15 \%$ is lower than for repeat mediastinoscopy. Finally, after the initial use of needle-based techniques, first cervical mediastinoscopy as a restaging technique seems to be the most effective method for assessing nodal disease after induction treatment and selecting potential candidates for surgery (fig. 2).

\section{References}

1 National Institute for Clinical Excellence (NICE), National Collaborating Center for Acute Care. Diagnosis and Treatment of Lung Cancer. NICE, London, 2005. www.nice.org.uk/nicemedia/pdf/cg024fullguideline.pdf

2 Jemal A, Thun MJ, Ries LA, et al. Annual report to the nation on the status of cancer, 1975-2005, featuring trends in lung cancer, tobacco use and tobacco control. J Natl Cancer Inst 2008; 100: 1672-1694.

3 Statistisches Bundesamt. Statistisches Jahrbuch 2007 Für die Bundesrepublik Deutschland [Statistical Yearbook 2007 for the Federal Republic of Germany]. Wiesbaden, Statistisches Bundesamt (Federal Statistical Office), 2007. www.destatis.de/DE/Publikationen/StatistischesJahrbuch/Jahrbuch2007.pdf?_blob=publicationFile

4 Eberhardt W, Wilke H, Stamatis G, et al. Preoperative chemotherapy followed by concurrent chemoradiation therapy based on hyperfractionated accelerated radiotherapy and definitive surgery in locally advanced non-small cell lung cancer: mature results of a phase II trial. J Clin Oncol 1998; 16: 622-634.

5 Thomas M, Rübe C, Semik M, et al. Chemotherapy and subsequent twice-daily chemoradiation before surgery in stage III non-small cell lung cancer: impact of tumour regression on survival. J Clin Oncol 1999; 17: 1185-1193. 
6 van Meerbeeck JP, Kramer GW, Van Schil PE, et al. Randomized controlled trial of resection versus radiotherapy after induction chemotherapy in stage IIIA-N2 non-small-cell lung cancer. J Natl Cancer Inst 2007; 99: 442-450.

7 Albain KS, Swann RS, Rusch VW, et al. Radiotherapy plus chemotherapy with or without surgical resection for stage III non-small-cell lung cancer: a phase III randomised controlled trial. Lancet 2009; 374: 379-386.

8 Goeckenjan G, Sitter H, Thomas M, et al. Prevention, diagnosis, therapy, and follow-up of lung cancer: interdisciplinary guideline of the German Respiratory Society and the German Cancer Society. Pneumologie 2011; 65: 39-59.

9 Wahidi MM, Covert JA, Goudar RK, et al. Evidence of the treatment of patients with pulmonary nodules: when is it lung cancer? ACCP evidence-based clinical practice guidelines (2nd edition). Chest 2007; 42: 94S-107S.

10 MacDonald SL, Hansell DM. Staging of non-small cell lung cancer: imaging of intrathoracic disease. Eur J Radiol 2003; 45: 18-30.

11 Komaki R, Putnam JB Jr, Walsch G, et al. The management of superior sulcus tumours. Semin Surg Oncol 2000; 18: $152-164$.

12 Hellwig D, Ukena D, Paulsen F, et al. Metaanalyse zum Stellenwert der Positronen-Emissions-Tomographie mit F-18-Fluorodesoxyglykose (FDG-PET) bei Lungentumouren [Meta-analysis of the efficacy of positron emission tomography with F-18-fluorodeoxyglucose in lung tumors]. Pneumologie 2001; 55: 367-377.

13 Ung YC, Maziak DE, Vanderveen JA, et al. 18 Fluorodeoxyglucose positron emission tomography in the diagnosis and staging of lung cancer: a systematic review. J Natl Cancer Inst 2007; 99: 1753-1767.

14 Honeybourne D, Babb J, Bowie P, et al. British Thoracic Society guidelines on diagnostic flexible bronchoscopy. Thorax 2001; 56: Suppl. 1, i1-i21.

15 Eberhardt R, Anantham D, Herth F, et al. Electromagnetic navigation diagnostic bronchoscopy in peripheral lung lesions. Chest 2007; 131: 1800-1805.

16 Kurimoto N, Miyazawa T, Okimasa S, et al. Endobronchial ultrasonography using a guide sheath increases the ability to diagnose peripherical pulmonary lesions endoscopically. Chest 2004; 126: 959-965.

17 Varadarajulu S, Schmulewitz N, Wildi SM, et al. Accuracy of EUS in staging of T4 lung cancer. Gastrointest Endosc 2004; 59: 345-348.

18 Ohno Y, Hatabu H, Takenada D, et al. CT-guided transthoracic needle aspiration biopsy of small $(\leqslant 20 \mathrm{~mm})$ solitary pulmonary nodules. AJR Am J Roentgenol 2003; 180: 1665-1669.

19 Hartmann TE. Radiologic evaluation of the solitary pulmonary nodule. Semin Thorac Cardiovasc Surg 2002; 14: 261-267.

20 Yamagami T, Iida S, Kato T, et al. Combining fine-needle aspiration and core biopsy under CT fluoroscopy guidance: a better way to treat patients with lung nodules? AJR Am J Roentgenol 2003; 180: 811-815.

21 De Giacomo T, Rendina EA, Venuta F, et al. Thoracoscopic staging of IIIB non-small cell lung cancer before neoadjuvant therapy. Ann Thor Surg 1997; 64: 1409-1411.

22 Sebastián-Quetglás F, Molins L, Baldó X, et al. Spanish Video-assisted Thoracic Surgery Study Group. Clinical value of video-assisted thoracoscopy for preoperative staging of non-small cell lung cancer. A prospective study of 105 patients. Lung Cancer 2003; 42: 297-301.

23 Marra A, Hillejan L, Zaboura G, et al. Pathologic N1 non-small cell lung cancer: correlation between pattern of lymphatic spread and prognosis. J Thorac Cardiovasc Surg 2003; 125: 543-553.

24 Rosell R, Maestre J, Front A, et al. A randomized trial of mitomycin/ifosfamide/cisplatin preoperative chemotherapy plus surgery versus surgery alone in stage IIIA non-small cell lung cancer. Semin Oncol 1994; 21: 28-33.

25 Albain KS, Rusch VW, Crowley JJ, et al. Concurrent cisplatin/etopside plus chest radiotherapy followed by surgery for stagesc IIIA(N2) and IIIB non-small cell lung cancer: mature results of Southwest Oncology Group phase II study 8805. J Clin Oncol 1995; 13: 1880-1992.

26 Depierre A, Westeel V, Jacoulet P. Preoperative chemotherapy for non-small cell lung cancer. Cancer Treat Rev 2001; 27: 119-127.

27 Betticher DC, Hsu Schmitz SF, Totsch M, et al. Prognostic factors affecting long-term outcomes in patients with resected stage IIIApN2 non-small cell lung cancer: 5 year follow-up of a phase II study. Br J Cancer 2006; 94: 1099-1106.

28 Stamatis G, Eberhardt W, Stüben G, et al. Preoperative chemoradiotherapy and surgery for selected non-small cell lung cancer IIIB subgroups: long term results. Ann Thorac Surg 1999; 68: 1144-1149.

29 Grunenwald DH, Andre F, Le Péchoux C, et al. Benefit of surgery after chemoradiotherapy in stage IIIB (T4 and/ or N3) non-small cell lung cancer. J Thorac Cardiovasc Surg 2001; 122: 796-802.

30 DeCamp MM, Rice TW, Adelstein DJ, et al. Value of accelerated multimodality therapy in stage IIIA and IIIB non-small cell lung cancer. J Thorac Cardiovasc Surg 2003; 126: 17-27.

31 Naruke T, Suemasu K, Ishikawa S. Lymph node mapping and curability at various levels of metastasis in resected lung cancer. J Thorac Cardiovasc Surg 1978; 76: 833-839.

32 Mountain C, Dresler C. Regional lymph node classification for lung cancer staging. Chest 1997; 111: 1718-1723.

33 Rusch VW, Asamura H, Watanabe $\mathrm{H}$, et al. The IASLC lung cancer staging project: a proposal for a new international lymph node map in the forthcoming seventh edition of the TNM classification for lung cancer. J Thorac Oncol 2009; 4: 568-577.

34 De Leyn P, Dooms C, Kuzdzal J, et al. Revised ESTS guidelines for preoperative mediastinal lymph node staging for non-small cell lung cancer. Eur J Cardiothorac Surg 2014; 45: 787-798.

35 Toloza EM, Harpole L, McCrory DC, et al. Noninvasive staging of non-small cell lung cancer: a review of the current evidence. Chest 2003; 123: 137S-146S.

36 Silvestri GA, Gonzales AV, Jantz MA, et al. Methods for Staging Non-small cell Lung Cancer. Diagnosis and management of Lung Cancer, 3rd ed: American College of Chest physicians Evidence-Based Clinical Practice Guidelines. Chest 2013; 143: 211S-250S.

37 Lardinois D, Weder W, Hany TF, et al. Staging of non-small cell lung cancer with intergrated positron-emission tomography and computed tomography. N Engl J Med 2003; 348: 2500-2507.

38 Cerfolio RJ, Ojha B, Brant AS, et al. The accuracy of integrated PET-CT compared with dedicated PET alone for the staging of patients with non-small cell lung cancer. Ann Thorac Surg 2004; 78: 1017-1023.

39 Halpern BS, Schiepers C, Weber WA, et al. Presurgical staging of non-small cell lung cancer. Positron emission tomography, intergrated positron emission tomography/CT, and software image fusion. Chest 2005; 128: 2289-2297. 
De Leyn P, Lardinois D, van Schil PE, et al. ESTS guidelines for preoperative lymph node staging for non-small cell lung cancer. Eur J Cardiothorac Surg 2007; 32: 1-8.

41 Hishida T, Yoshida J, Nishimura M, et al. Problems in the current diagnostic standards of clinical N1 non-small cell lung cancer. Thorax 2008; 63: 526-531.

42 Gomez-Caro A, Boada M, Cabanas M, et al. False-negative rate after positron emission tomography/computer tomography scan for mediastinal staging in clinical I stage non-small cell lung cancer. Eur J Cardiothorac Surg 2012; 42: 93-100.

43 Lee PC, Port JL, Korst RJ, et al. Risk factors for occult mediastinal metastasis in clinical stage I non-small cell lung cancer. Ann Thorac Surg 2007; 84: 177-181.

44 Holty J, Kuschner W, Gould M. Accuracy of transbronchial needle aspiration for mediastinal staging of non-small cell lung cancer: a meta-analysis. Thorax 2005; 60: 949-955.

45 Herth FJ, Eberhardt R, Krasnik M, et al. Endobronchial ultrasound-guided transbronchial needle aspiration of lymph nodes in the radiologically and positron emission tomography-normal mediastinum in patients with lung cancer. Chest 2008; 133: 887-891.

46 Yasufuku K, Pierre A, Darling G, et al. A prospective controlled trial of endobronchial ultrasound-guided transbronchial needle aspiration compared with mediastinoscopy for mediastinal lymph node staging of lung cancer. J Thorac Cardiovasc Surg 2011; 142: 1393-1400.

47 Talebian M, von Bartheld MB, Braun J, et al. EUS-FNA in the preoperative staging of non-small cell lung cancer. Lung Cancer 2010; 69: 60-65.

48 Annema JT, Bohoslavsky R, Burgers S, et al. Implementation of endoscopic ultrasound for lung cancer staging. Gastrointest Endosc 2010; 71: 54-70.

49 Szlubowski A, Zielínski M, Soja J, et al. A combined approach of endobronchial and endoscopic ultrasound-guided needle aspiration in the radiologically normal mediastinum in non-small cell lung cancer staging-a prospective trial. Eur J Cardiothorac Surg 2010; 37: 1175-1179.

50 Herth FJ, Krasnik M, Kahn N, et al. Combined endoscopic-endobronchial ultrasound-guided fine-needle aspiration of mediastinal lymph nodes through a single bronchoscope in 150 patients with suspected lung cancer. Chest 2010; 138: 790-794.

51 Annema JT, van Meerbeeck JP, Rintoul RC, et al. Mediastinoscopy vs endosonography for mediastinal nodal staging of lung cancer: a randomized trial. JAMA 2010; 304: 2245-2252.

52 Ohnishi R, Yasuda I, Kato T, et al. Combined endobronchial and endoscopic ultrasound-guided fine needle aspiration for mediastinal nodal staging of lung cancer. Endoscopy 2011; 43: 1082-1089.

53 Lardinois D, Schallberger A, Betticher D, et al. Postinduction videomediastinoscopy is as accurate and safe as video-mediastinoscopy in patients without pretreatment for potentially operable non-small cell lung cancer. Ann Thorac Surg 2003; 75: 1102-1106.

54 Mouroux J, Venissac N, Alifano M, et al. Combined video-assisted medisatinoscopy and video-assisted thoracoscopy in the management of lung cancer. Ann Thorac Surg 2001; 72: 1698-1704.

55 De Leyn P, Lerut T. Videomediastinoscopy. In: Yim AP, Hazelrigg SR, Izzat MB, et al., eds. Minimal Access in the Cardiothoracic Surgery. Philadelphia, WB Saunders, 2000; pp. 169-174.

56 Zakkar M, Tan C, Hunt I. Is video mediastinoscopy a safer and more effective procedure than conventional mediastinoscopy. Interact Cardiovasc Thorac Surg 2012; 14: 81-84.

57 Ginsberg RJ, Rice TW, Goldberg M, et al. Extended cervical mediastinoscopy. A single staging procedure for bronchogenic carcinoma of the left upper lobe. J Thorac Cardiovasc Surg 1987; 94: 673-678.

58 Barendregt WB, Deleu HW, Joosten HJ, et al. The value of parasternal mediastinoscopy in staging of bronchial carcinoma. Eur J Cardiothorac Surg 1995; 9: 655-658.

59 Nechala P, Graham AJ, McFadden SD, et al. retrospective analysis of the clinical performance of anterior mediastinotomy. Ann Thorac Surg 2006; 82: 2004-2009.

60 Hürtgen M, Friedel G, Tomes H, et al. Radical video-assisted mediastinoscopic lymphadenectomy (VAMLA) technique and first results. Eur J Cardiothorac Surg 2002; 21: 348-351.

61 Kuzdzał J, Zieliński M, Papla B, et al. The transcervical extended mediastinal lymphadenectomy versus cervical mediastinoscopy in non-small cell lung cancer staging. Eur J Cardiothorac Surg 2007; 31: 88-94.

62 Zieliński M. Transcervical extended mediastinal lymphadenectomy: results of staging in two hundred fifty-six patients with non-small cell lung cancer. J Thorac Oncol 2007; 2: 370-372.

63 Eggeling S, Martin T, Böttger J, et al. Invasive staging of non-small cell lung cancer- a prospective study. Eur J Cardiothorac Surg 2002; 22: 679-684.

64 Massone PP, Lequaglie C, Magnani B, et al. The real impact and usefulness of video-assisted thoracoscopic surgery in the diagnosis and therapy of clinical lymphadenopathies of the mediastinum. Ann Surg Oncol 2003; 10: $1197-1202$.

65 Weder W, Schmid RA, Bruchhaus H, et al. Detection of extrathoracic metastases by positron emission tomography in lung cancer. Ann Thorac Surg 1998; 66: 886-892.

66 Eberhardt WE, Korfee S, Pöttgen C, et al. Randomized multicenter German Trial of surgery plus radiotherapy versus tri-modality treatment for operable stage IIIA NSCLC-long- term follow-up data. J Thorac Oncol 2007; 2: S310-S311.

67 Trodella L, Granone P, Valente S, et al. Neoadjuvant concurrent radiochemotherapy in locally advanced (IIIA-IIIB) non-small-cell lung cancer: long-term results according to downstaging. Ann Oncol 2004; 15: 389-398.

68 Bueno R, Richards W, Swanson S, et al. Nodal stage after induction therapy for stage IIIA lung cancer determines patient survival. Ann Thorac Surg 2000; 70: 1826-1831.

69 Junker K, Thomas M, Schulmann K, et al. Tumour regression in non-small cell lung cancer following neoadjuvant therapy. Histological assessment. J Cancer Res Clin Oncol 1997; 123: 469-477.

70 Martin J, Ginsberg RJ, Venkatraman ES, et al. Long-term results of combined-modality therapy in resectable non-small cell lung cancer. J Clin Oncol 2002; 15: 1989-1995.

71 Stamatis G, Djuric D, Eberhardt W, et al. Postoperative morbidity and mortality after induction chemoradiotherapy for locally advanced lung cancer: an analysis of 350 operated patients. Eur J Cardiothorac Surg 2002; 22: 292-297. 
72 Margaritora S, Cesario A, Galetta D, et al. Ten year experience with induction therapy in locally advanced non-small cell lung cancer (NSCLC): is clinical restaging predictive of pathological staging? Eur J Cardiothorac Surg 2001; 19: 894-898.

73 Cerfolio R, Ojha B, Mukherjee S, et al. Positron emission tomography scanning with 2-fluoro-2-deoxy-D-glycose as a predictor of response of neoadjuvant treatment for non-small cell lung carcinoma. J Thorac Cardiovasc Surg 2003; 125: 938-944.

74 Stamatis G. Risks of neoadjuvant chemotherapy and radiation therapy. Thorac Surg Clin 2008; 18: 71-80.

75 Choi N, Fischmann A, Niemierko A, et al. Dose-response relationship between probability of pathologic tumour control and glucose metabolic rate measure with FDG-PET after preoperative chemoradiotherapy in locally advanced non-small cell lung cancer. Int J Radiat Oncol Biol Phys 2002; 54: 1024-1035.

76 Eschmann SM, Friedel G, Paulsen F, et al. 18F-FDG PET for assessment of therapy response and preoperative re-evaluation after neoadjuvant radio-chemotherapy in stage III non-small cell lung cancer. Eur J Nucl Med Mol Imaging 2007; 34: 463-471.

77 Lardinois D. Pre- and intra-operative mediastinal staging in non-small cell lung cancer. Swiss Med Wkly 2011; 141: w13168.

78 Ohtsuka T, Nomori H, Ebihara A, et al. FDG-PET imaging for lymph node staging and pathologic tumour response after neoadjuvant treatment of non-small cell lung cancer. Ann Thorac Cardiovasc Surg 2006; 12: 89-94.

79 Cerfolio R, Bryant A, Ojha B, et al. Restaging patients with N2 (stage IIIa) non-small cell lung cancer after neoadjuvant chemoradiotherapy: a prospective study. J Thorac Cardiovasc Surg 2006; 131: 1229-1235.

80 De Leyn P, Stoobants S, Dewever W, et al. Prospective comparative study of integrated PET-CT versus remediastinoscopy in the assessment of residual mediastinal disease after induction chemotherapy for mediastinoscopy proven stage IIIa-N2 non-small cell lung cancer. J Clin Oncol 2006; 20: 3333-3339.

81 Pöttgen C, Levegrün S, Theegarten D, et al. Value of 18F-fluoro-2-deoxy-D-glucose-positron emission tomography/computed tomography in non-small cell lung cancer for prediction of pathologic response and times to relapse after neoadjuvant chemotherapy. Clin Cancer Res 2006; 12: 97-106.

82 Cerfolio R, Bryant A, Winokur T, et al. Repeat FDG-PET after neoadjuvant therapy is a predictor of pathologic response in patients with non-small cell lung cancer. Ann Thorac Surg 2004; 78: 1903-1909.

83 Herth FJF, Annema JT, Eberhardt R, et al. Endobronchial ultrasound with transbronchial needle aspiration for restaging the mediastinum in lung cancer. J Clin Oncol 2008; 26: 3346-3350.

84 Annema JT, Veselic M, Versteegh MI, et al. Mediastinal restaging: EUS-FNA offers a new perspective. Lung Cancer 2003; 42: 311-318.

85 Szlubowski A, Herth FJ, Soja J, et al. Endobronchial ultrasound-guided needle aspiration in non-small cell lung cancer restaging verified by the transcervical bilateral extended mediastinal lymphadenectomy - a prospective study. Eur J Cardiothorac Surg 2010; 37: 1180-1184.

86 Kunst PW, Lee P, Paul MA, et al. Restaging of mediastinal nodes with transbronchial needle aspiration after induction chemoradiation for locally advanced non-small cell lung cancer. J Thorac Oncol 2007; 2: 912-915.

87 Stamatis G, Fechner S, Hillejan L, et al. Repeat mediastinoscopy as a restaging procedure. Pneumologie 2005; 59: 862-866.

88 Van Schil P, Stamatis G. Sensitivity of remediastinoscopy: influence of adhesions, multilevel N2 involvement, or surgical technique? J Clin Oncol 2006; 24: 5338.

89 De Waele M, Serra-Mitjans M, Hendriks J, et al. Accuracy and survival of repeat mediastinoscopy after induction therapy for non-small cell lung cancer in a combined series of 104 patients. Eur J Cardiothorac Surg 2008; 33: $824-828$.

90 Marra A, Hillejan L, Fechner S, et al. Remediastinoscopy in restaging of lung cancer after induction therapy. $J$ Thorac Cardiovasc Surg 2008; 135: 843-849.

91 Zielinski M, Hauer L, Hauer J, et al. Non-small cell lung cancer restaging with transcervical extended mediastinal lymphadenectomy. Eur J Cardiothorac Surg 2010; 37: 776-780.

92 Zielinksi M, Szlubowski A, Kolodziej M, et al. Comparison of endobronchial ultrasound and/or endoesophageal ultrasound with transcervical extended mediastinal lymphadenectomy for staging and restaging of non-small-cell lung cancer. J Thorac Oncol 2013; 8: 630-636.

93 Candela S, Detterbeck FC. A systematic review after induction therapy for stage IIIa lung cancer. prediction of pathologic stage. J Thorac Oncol 2010; 5: 389-398.

94 Jaklitsch MT, Gu L, Demmy T, et al. Prospective phase II trial of preresection thoracoscopic mediastinal restaging after neoadjuvant therapy for IIIA (N2) non-small cell lung cancer: results of CALGB Protocol 39803. J Thorac Cardiovasc Surg 2013; 146: 9-16. 